\title{
Investigation of Safety Factors through Frequency and Severity Importance Index in Iranian Construction Project
}

\author{
Keivan Ahmadi ${ }^{1}$, Mahdi Rafieizonooz ${ }^{2 *}$ \\ ${ }^{1}$ Faculty member of lamei gorgani higher educational institute, Gorgan, Iran \\ ${ }^{2}$ Retrofitting of Gas Equipment Against Earthquake, Tehran Gas Province Company, Iran \\ Received: 03/01/2020 \\ Accepted: 04/03/2020 \\ Published: 20/03/2020
}

\begin{abstract}
The high rate of injuries in Tehran construction indicated that safety program may be neglected. This research has been conducted to identify root causes of accidents in Tehran construction projects and to propose ways to mitigate them. Accident causation factors divided in two groups based on reviewing literatures as follow, distal and proximal factors. The analysis on distal factors shows that the distal factors of accident causation in Tehran are result because of many issues and causes. Some of the serious factors are 'Cash flow problems', 'inadequate budget for supervision', 'Lack of relevant experience', 'Recruit untrained operatives' and 'Reduce project budget'. By analyzing successful safety program implementation factors, the view of respondents indicates that general management in Tehran companies, are not completely committed to safety program and try to neglect safety. Moreover, the departments of labour's inspectors regularly neglect inspections. On the other hand, lack of workers participation in safety program, has the potential for causing accidents which cause the safety program unsuccessful. Finally, for mitigating and preventing accidents in Tehran construction site, some recommendations have been made as follow: 'Management should assign adequate budget for designing Section', 'Management should have enough and relevant experience and knowledge about the projects' and 'Management should recruit trained operative who has enough skill relevant with projects.
\end{abstract}

Keywords: Tehran, Safety factors, Construction, presentation methods

\section{Introduction}

Currently one of the main economic forces in Iran is construction industry and it is recognized as one of the most dangerous industry because of its unique nature (Jannadi and Bu-Khamsin, 2002 and Shahram Mahmoudi et al. 2015). According to the Social Security Organization (SOCSO) report in 2016, almost $40 \%$ of total accidents occurred in Iranian construction area. In addition of death and injuries to workers, accidents have some negative effects on construction project such as wasting cost, irregular construction schedule, damage to renown of company and impact on workers' psychology (Tam, Zeng et al. 2004, Seok J. Yoon et. Al. 2013 and Sunku Venkata Siva Rajaprasad \& Pasupulati Venkata Chalapathi 2015). Thus "Good safety and health practices are an asset, not a cost. Improving workplace safety and health is an important part of building an efficient, skilled economy and improving quality of life". (Mr. Hasegawa.2005 and Kwesi Amponsah-Tawiah et al. 2016). Therefore, the aim of this research is to identify causes of accidents in construction project and the impact to the projects itself. In fact, causes of accidents can be investigated in three sections such as, root causes, surface causes and direct causes of accidents. In this research root causes of accidents will be identified, whereas mitigation in root causes lead to decrease occurrence of surfaces causes and at last declining accidents. According to SOCSO the number of construction accidents in Iran in 2016, is shown in Table 1. Statistic and fatality rate demonstrated that the construction accidents in Iran have become a critical

Corresponding author: Mahdi Rafieizonooz, Retrofitting of Gas Equipment Against Earthquake, Tehran Gas Province Company, Iran. E-mail: mahdi.rafieizonooz@gmail.com

https://doi.org/10.47277/JEEP/1(1)28 problem that need an enormous and quick overhaul from the existing site safety practices. Safety issues are being neglected by Iranian companies. They more focus on extra profit, instead of emphasizing on safety. Maybe they do not know how cost of an accident can be huge, while they can prevent accident by only spending little time and cost. Approximately $85 \%$ of construction accidents in Iran which occurred because of human negligence are preventable (Esabati 2010).

Table 1: The number of construction accident in Iran 20162017

\begin{tabular}{ll}
\hline Slips & 1400 \\
Falls from height & 651 \\
Working with machinery & 748 \\
Trapped by something collapsing & 325 \\
Contact with electricity & 130 \\
\hline Total & 3,254 \\
\hline
\end{tabular}

\section{Definition of Accidents}

"It is essential to explain what we mean by the word of "accident", because before anyone can begin to put up any sort of a flight, he must know his enemy" (Hollnagel, 2004). Accident is defined in different ways. Some of the main definitions are as shown in Table 2. In summary, an accident is an unplanned, undesired, and uncontrolled event which led or could have led to property damage, injury to persons or some other loss. For preventing accidents, the first step is to know how accidents happen (Fakhradin Ghasemi et al. 2015). Many researches have been tried to find about accident causation models in industrial applications. Generally, the purpose of these modelling is to prepare tools for improving accident prevention plans. In fact, accidents do not just happen. It means that" many different contributory factors give rise to accidents" (Petersen`s Multiple Causation Theory, 
Table 2: Accident Definitions

\begin{tabular}{lcc}
\hline \multicolumn{1}{c}{ Accident Definition } & By & Year \\
\hline $\begin{array}{l}\text { An undesired and unexpected disturbance of the normal completion of the work process, which is } \\
\text { generally brought about by the combination of internal or external factors of a technical, physical, } \\
\text { or social nature and which leads to injuries. }\end{array}$ & Neuloh & 1957 \\
$\begin{array}{l}\text { Accident is an unintentional event. Accident does not necessarily cause an injury, where damage } \\
\text { to tools, equipment, and materials can also be considered as accident. Thus, accident which results } \\
\text { in injury to human receives the greatest attention and concern. }\end{array}$ & Hinze & 1957 \\
$\begin{array}{l}\text { An unplanned and uncontrolled event that is not necessarily injurious or damaging to an } \\
\text { individual, property, or to an operation. Any unplanned event that interrupts or interferes with the } \\
\text { orderly progress of a production activity or process. }\end{array}$ & $\begin{array}{c}\text { Confer } \\
\text { on }\end{array}$ & 1994
\end{tabular}

Accident is defined as an unpleasant event that happens unexpectedly and cause injury or damage. Oxford 2010

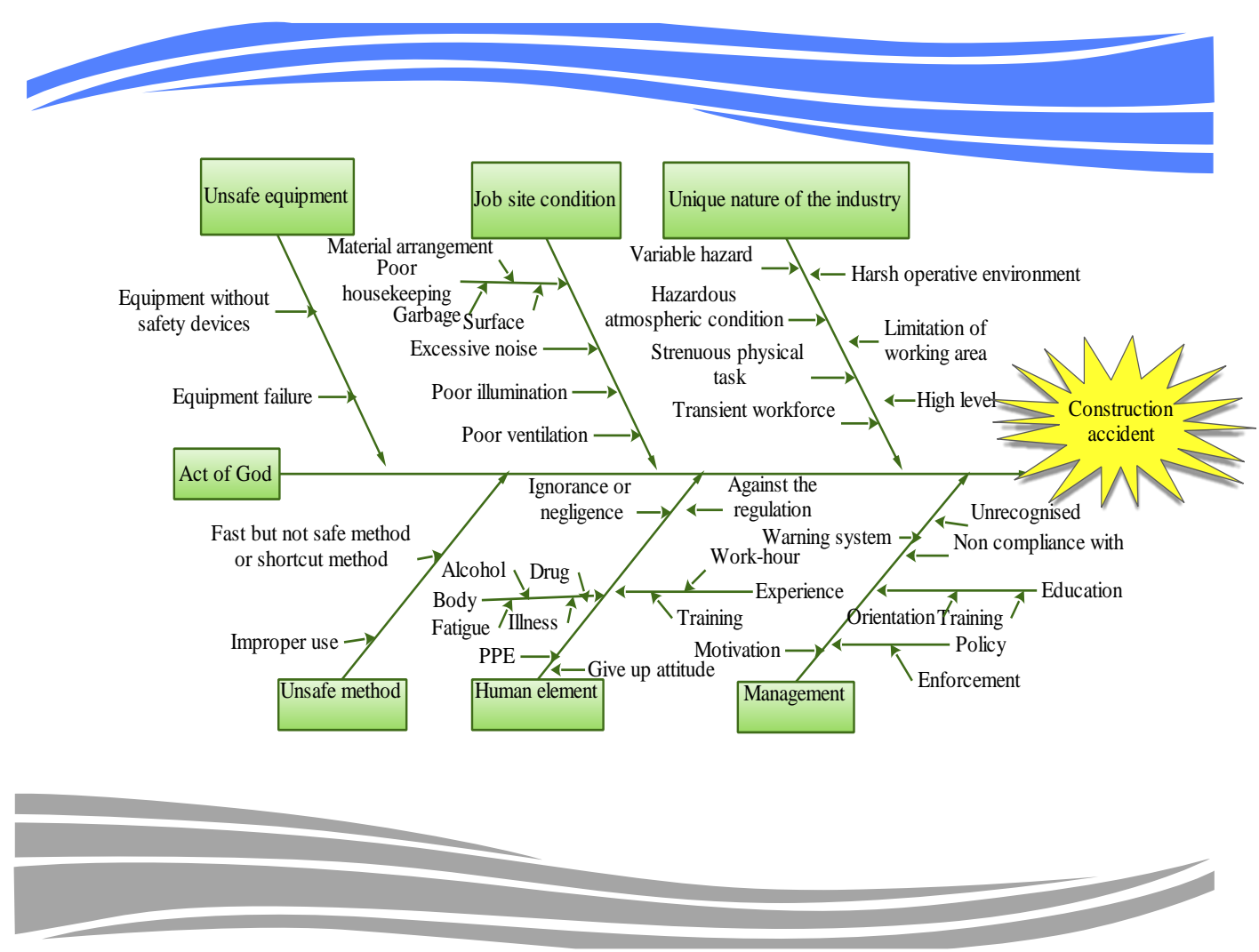

Figure 1: Factors Affecting the Occurance of Accident

\subsection{Heinrich's Domino Theory}

There are several domino theories. The main theory of domino was presented by Herbert William Heinrich while working at Travelers Insurance Company in 1929. He suggests five metaphorical dominoes which labeled with accident causes which are listed in order as fallow: social environment and ancestry, fault of person, unsafe acts or condition, accidents, and injuries. This theory explains that accidents result from a chain of sequential events which metaphorically similar to line of dominoes falling over. It means that falling of first domino will trigger the next one, and next, until the last domino falls, which shows loss. In fact, Heinrich tried to explain that accidents could be prevented by eliminating any one of the dominos in sequence.

\subsection{Bird's Domino Theory}

In 1960s Frank Bird Jr. refined and slightly changed by emphasizing on management and incident as property loss. In fact, Bird's theory was same as Heinrich's Domino Theory; nevertheless the five factors were different. The five updated factors are management- loose of control, origins- basic causes, symptoms-immediate causes, contact- incidents and loss- people - property. The root causes result from first and second domino which mentioned as loose of control and the basic causes which related to human such as a lack of skill, knowledge and ability and work condition such as inadequate maintenance, work standards. These causes arise from a lack of appropriate control, such as, lack of inadequate control programs, inadequate program for implementation. For instance, lack of training courses for operators in risky condition, or courses are below the required standards. Moreover, other researchers also updated Heinrich's Domino Theory such as; Adams (1976) stressed on the organizational structure of the management, although Weaver (1971) emphasized on the significant to identify the root of unsafe 
acts or conditions which related to the management

\subsection{Modern Causation}

In modern causation theory (Parallel Heinrich`s to a point) is shown that how chain of errors causes accidents, also how to correct those causes. In this theory the term of operating error is used instead of unsafe act and unsafe condition (Domino theory), mishap is used rather than accident and injury for avoiding the famous misunderstanding that an accident essentially includes damage or injury, finally injury that is called result.

\subsection{Constraint - Response Theory}

Suraji Duff and Peckitt (2001) have updated a causal model which specific to construction accidents. They classified the causes of accidents into proximal and distal factors which may be activated by actions of clients, designers and operatives. As shown in Figure 2 in Constraint Response theory distal factors are root causes of accident which are like as first and second dominos in Domino theory 'Management: Loss of control' and 'Origins: Basic causes'. Also proximal factors are like as third domino 'Symptoms: Immediate causes'.

\subsection{Causes of Accidents:}

\subsubsection{Distal Factors (Root Causes)}

As shown in Figure 3, based on Constraint - Response Theory, distal factors were observed to include constraints of the project conception, project design, project management, construction management, subcontractors and operatives who precipitate potentially unsafe responses by clients, designers, the client's project team, contractors, subcontractors and responsibilities in preventing accidents.

operatives (Suraji et al. 2001). These distal factors include the influence of management and organizational factors, environmental factors, and individual factors of the participants (Suraji et al. 2001).

\subsubsection{Proximal Factors (Impact of Root Causes)}

Impact of root causes or proximal factors causing construction accidents can be identified as inappropriate processes (such as construction planning, construction control and construction operation), site conditions and operative actions. Figure 4 indicates the detail causes of accident in each category of proximal factors.

\section{Methods}

Data for this research were collected by distributing questionnaire among targeted respondents who are involved with the issue of safety in Tehran's construction industry. After collecting data through questionnaire, some interviews were done with carefully selected respondents to increase the accuracy of this research.

\subsection{Data Analysis}

After gathering information and data through questionnaire, data were analyzed by using SPSS software and were presented in the form of tables. For data analyzing there some methods which are as follows: a) relative Important Index (RII) for Frequency and Severity; b) likert Scale; and c) reliability test (Crombach's Alpha).

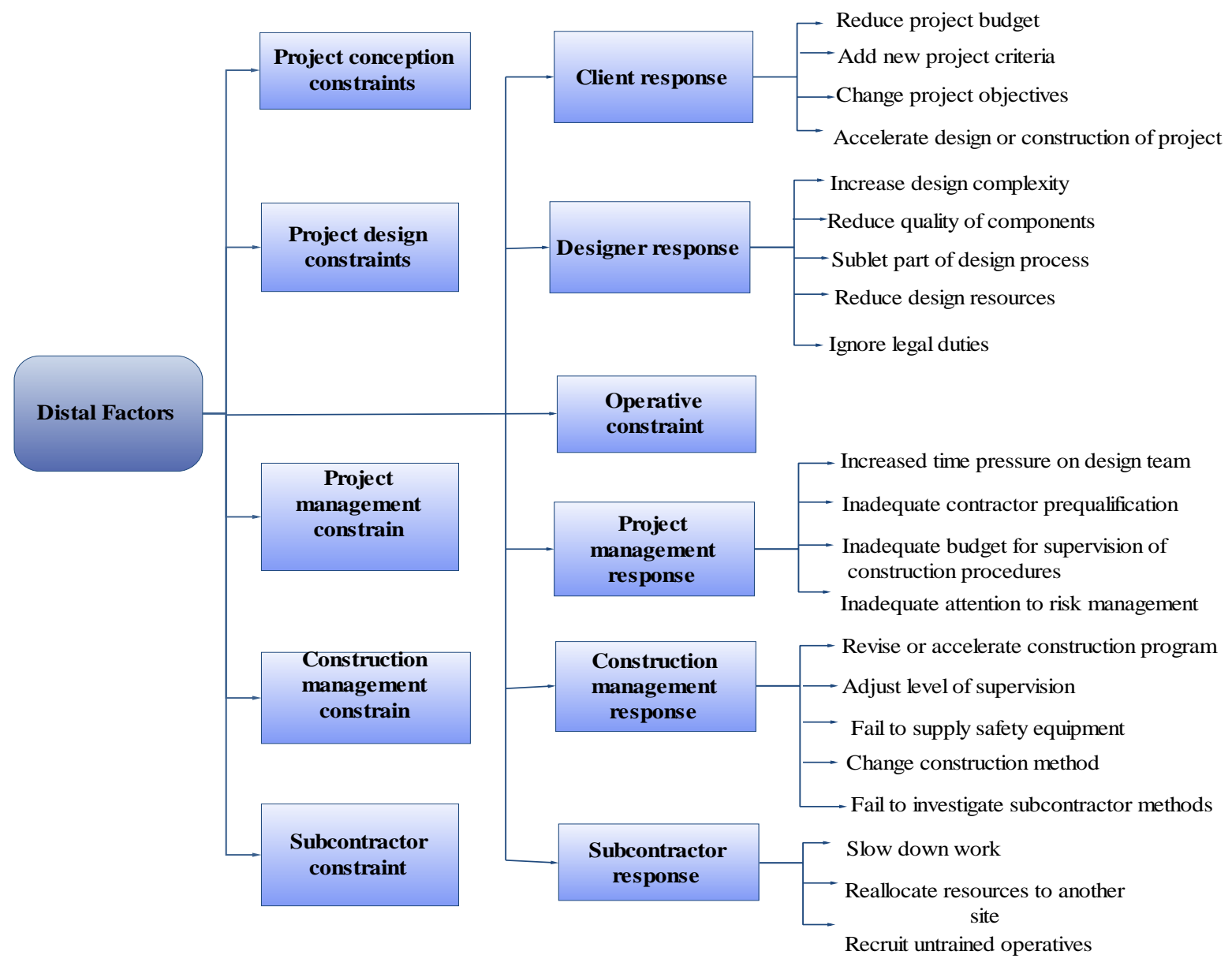




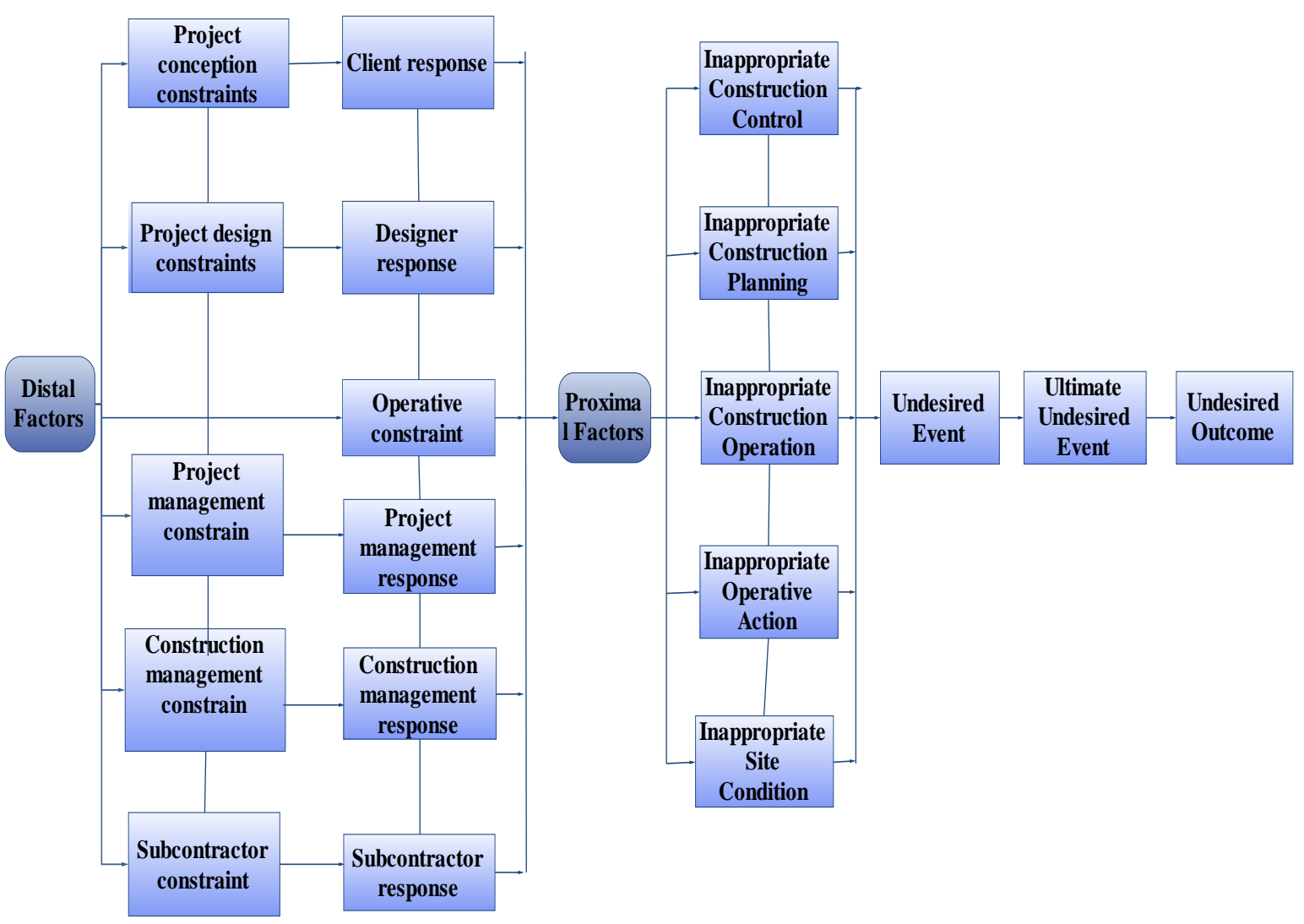

Figure 3: Distal Factors (Root Causes)

\subsection{Calculation of RII}

According to Mohd Najib Abdul Ghafar (2003) the Relative Importance Index (RII) was calculated by following formulas:

$\mathrm{I}=\Sigma \mathrm{W}_{\mathrm{i}} / \mathrm{B}^{*} \mathrm{~N}$

where $\mathrm{i}$ is answer group index, $\mathrm{Wi}$ is the weight assigned to each answer, (i from 1 to N), B is the highest amount of score for each cause (here 5), and $\mathrm{N}$ is the number of valid responses. The main root causes of safety are organized in ascending order of ranks, cause with highest rank or RII 5 designates that it has the greatest impact on the happening of accidents although the Cause with lowest RII designates that it has the minimum impact on happening accidents in construction projects.

\subsection{Likert Scaling Method}

According to Mohd Najib Abdul Ghafar (2003) Likert scaling method is a multiple-choice inquiry where several choices of answers are given from positive to negative views. For this research, Likert scaling method was used to establish the total score gained by the requirements from four section questions. As shown in Table 3, the scales from 1 to 5 were used to consider the frequency of the root causes of accidents where 1 is considered as least frequent (never) while 5 is most frequent (always). Moreover, the scales from 1 to 5 were used to consider the severity of distal and proximal factors of accidents based on each type where 1 is determined as no severe while 5 is for the most severe. Additionally, the scales from 1 to 5 were used to consider the degree of implementation on safety program where 1 is determined as to no extent where 5 is considered as to a very great extent. For considering the level of frequency, severity and implementation of safety program in construction site mean score were used.

Table 3: Scale Indicators of Likert Scaling Method for Frequency, Severity and Degree of Implementation

\begin{tabular}{rllll}
\hline Scale & Frequency & Severity & Degree of Implementation & Index \\
1 & Never & Not Severe & to no extent & $1.00 \geq$ Mean Index $<1.50$ \\
2 & Seldom & Less Severe & To slightly extent & $1.50 \geq$ Mean Index $<2.50$ \\
3 & Half of the time & Moderate & Moderate & $2.50 \geq$ Mean Index $<3.50$ \\
4 & Often & Severe & To a great extent & $3.50 \geq$ Mean Index $<4.50$ \\
5 & Always & Very Severe & To a very great extent & $4.50 \geq$ Mean Index $\leq 5.00$ \\
\hline
\end{tabular}




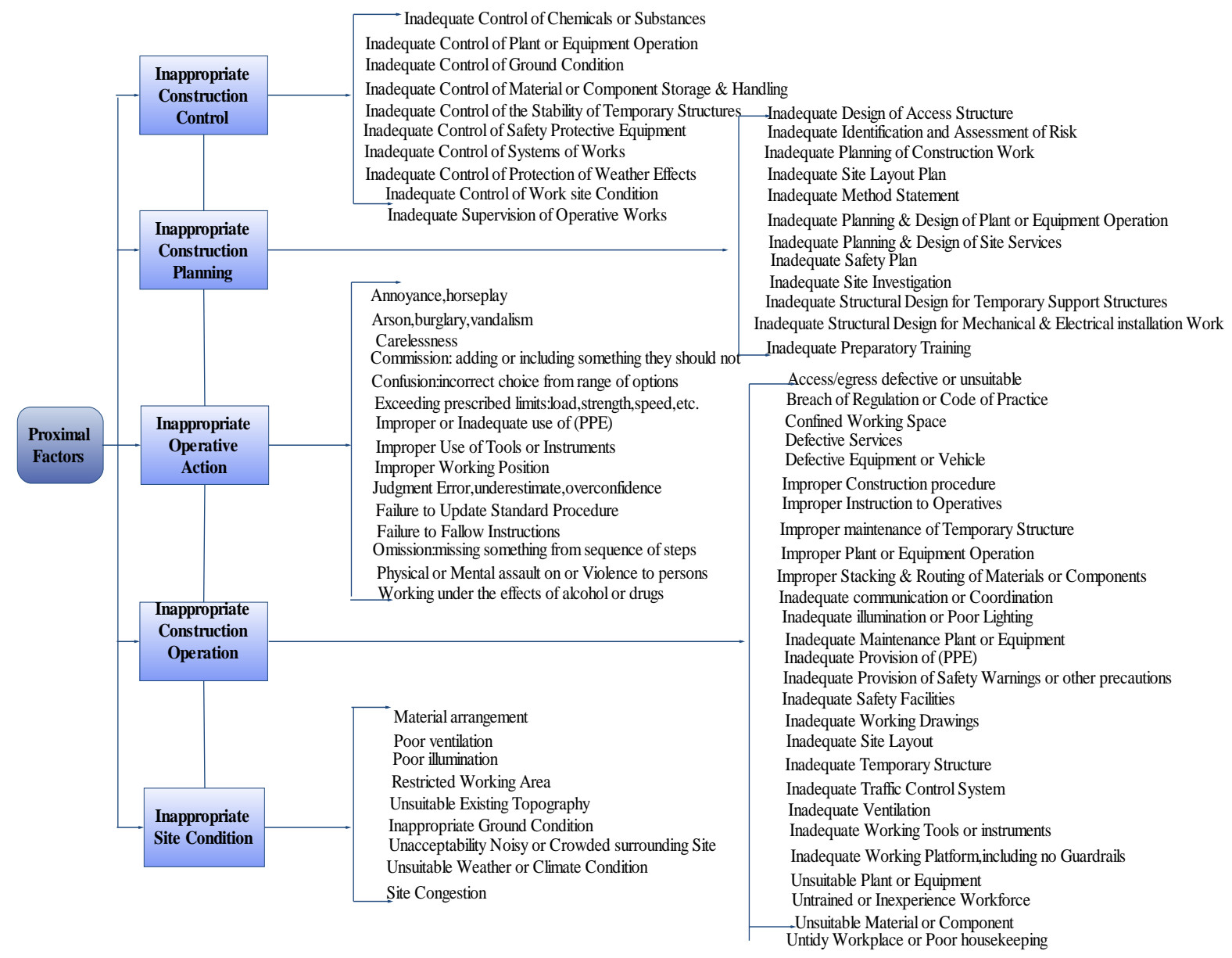

Figure 4: Proximal Factors (Impact of root causes)

Mohd najib abdul ghafar (2003) indicated that mean is an average score for a number of scores. Also it is determined as the way of the respondents whereby for this research, it shows the frequency, severity and implementation of safety program to establish the problem statement.

\subsection{Cronbach's Alpha Reliability Coefficient}

To ensure the achieved results were correct statistical reliability test was performed to analyse the data. Cronbach's alpha reliability coefficient demonstrated the internal consistency of the items within the scale. Also, for a given sample, it gives a unique estimate of reliability. Cronbach's alpha is the average value of the reliability coefficients, which would be obtained for all possible combinations of items when split into two half tests (Gliem and Gliem, 2003). Range of Internal Consistency Cronbach's alpha is shown in Table 4.

Table 4: Range of Internal Consistency Cronbach's alpha

\begin{tabular}{ll}
\hline Cronbach's alpha & Internal consistency \\
\hline $\boldsymbol{\alpha} \geq 0.9$ & Excellent \\
$0.9>\boldsymbol{\alpha} \geq 0.8$ & Good \\
$0.8>\boldsymbol{\alpha} \geq 0.7$ & Acceptable \\
$0.7>\boldsymbol{\alpha} \geq 0.6$ & Questionable \\
$0.6>\boldsymbol{\alpha} \geq \mathbf{0 . 5}$ & Poor \\
$\mathbf{0 . 5}>\boldsymbol{\alpha}$ & Unacceptable \\
\hline
\end{tabular}

\section{Discussion}

From 50 questionnaires which sent to Tehran construction sites, twenty-eight questionnaires were returned by the respondents. This survey by giving better understanding of the views of construction practitioners can help to prepare safety management instructions.

\subsection{Analytical Results of General Information about Construction Project}

The first section of questionnaires reported the general information about the respondents and the on-going project as stipulated in Table 5 below.

\subsection{Analytical Results on Frequency of root causes and Severity of root causes}

From literature especially based on constraint-response theory root causes categorized to eleven groups as follows: Project conception constraints, Project management constraint, Project design constraints, Construction management constraint, Subcontractor constraint, Operative constraint, Client responses, Project management response, Designer response, Construction management response and Subcontractor response. This finding indicates the respondents view and experience on root causes that are commonly occurred at Tehran construction sites. The results of this study can be compared to the findings of (Adeleke et al. 2018). Also, the analytical results will help the company to prevent accident occur. Figure 5 show that the level of frequency of root causes in Tehran construction site. Furthermore, Figure 6 indicates the level of severity of root causes which effect on construction industry in Tehran. Table 6 indicates the level of reliability of data and according to chapter 3 if data is more than 0.8 , then reliability of data is good. 
Table 5: Responds to General Information of Construction Projects in Tehran, Iran

\begin{tabular}{llll}
\hline General Information & & Responds & Percentage \\
Project Information & Government Project & 15 & $53.6 \%$ \\
Designation & Private Project & 13 & $46.4 \%$ \\
& Project Management & 8 & $28.6 \%$ \\
& Construction Management & 6 & $21.4 \%$ \\
& site Manager & 14 & $50.0 \%$ \\
Background Knowledge & Architect & 1 & $3.6 \%$ \\
& Civil Engineer & 27 & $96.4 \%$ \\
Experienced & Others & 0 & $.0 \%$ \\
& $<1$ year & 0 & $.0 \%$ \\
& $1-5$ years & 11 & $39.3 \%$ \\
Critical Safety Problem & $5-10$ years & 11 & $39.3 \%$ \\
Seriousness of the Accident & $>10$ years & 6 & $21.4 \%$ \\
& Yes & 27 & $96.4 \%$ \\
Accident Experienced & No & 1 & $3.6 \%$ \\
& Not serious & 3 & $.0 \%$ \\
\hline
\end{tabular}

Frequency Level

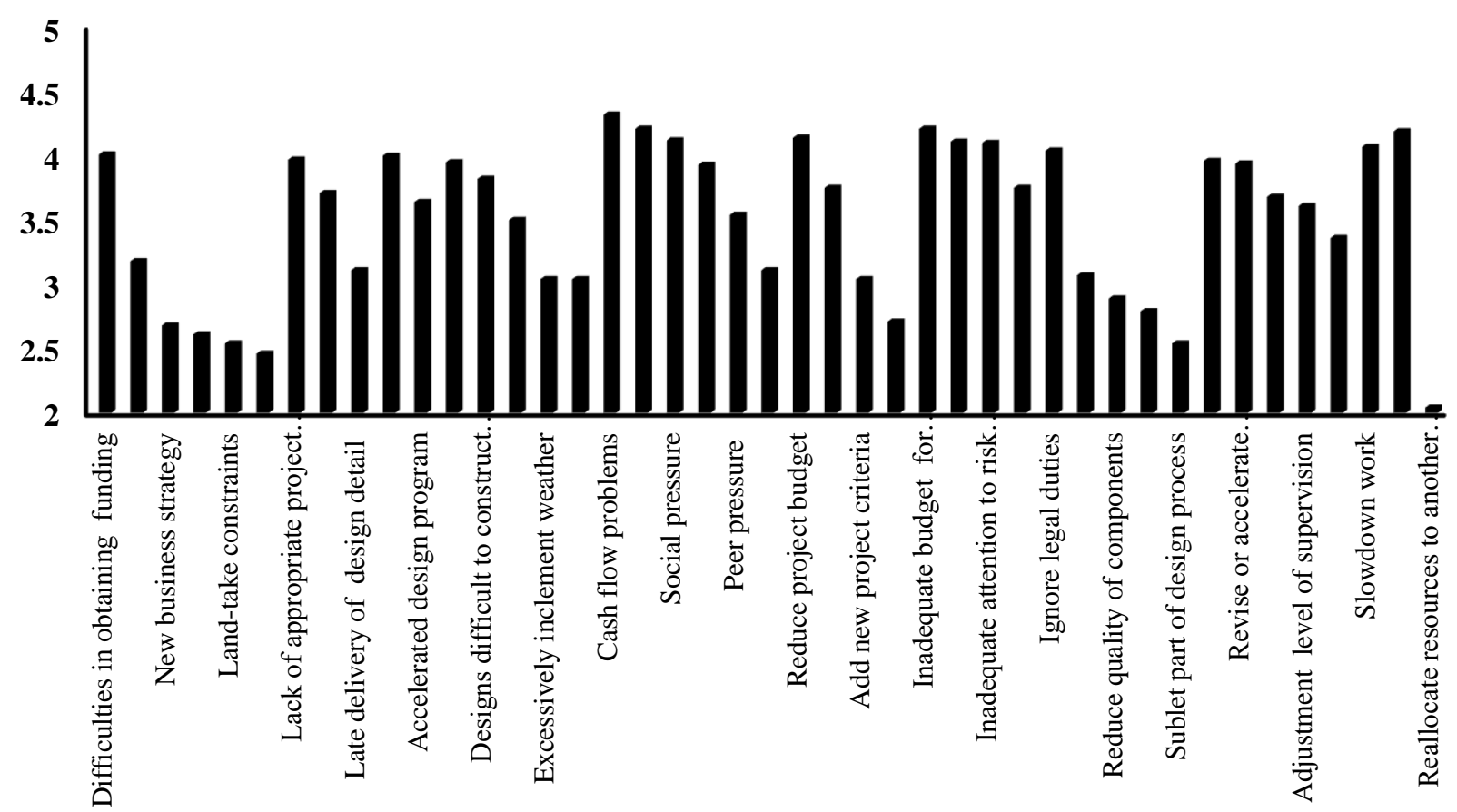

Figure 5: Frequency of Root Causes of Accidents in Construction site 


\section{Severity Level}

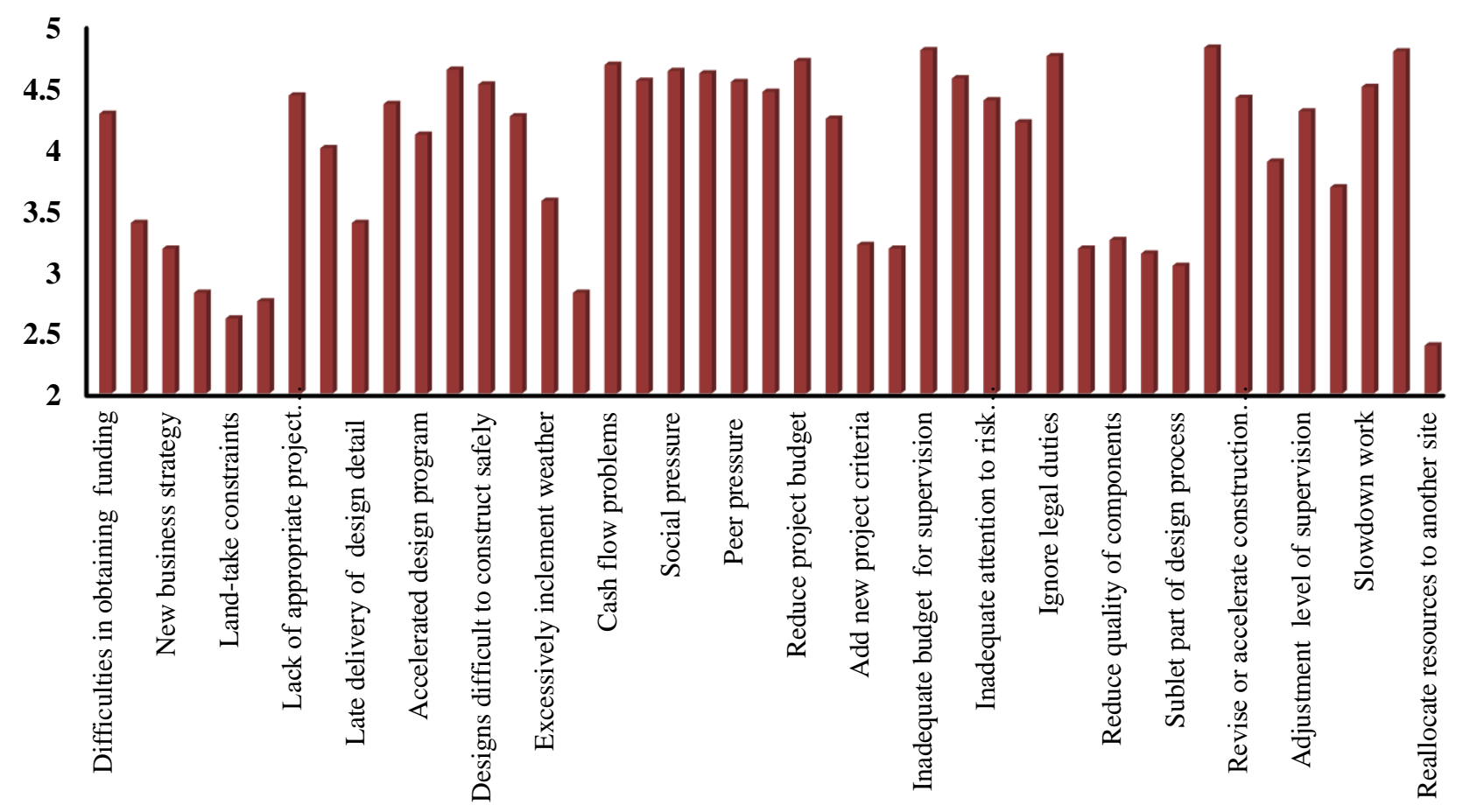

Figure 6: Severity of Root Causes of Accidents in Construction site

Table 6: Reliability of Data

\begin{tabular}{llll}
\hline & $\begin{array}{l}\text { Cronbach's } \\
\text { Alpha }\end{array}$ & $\begin{array}{l}\text { Cronbach's Alpha } \\
\text { Based on } \\
\text { Standardized Items }\end{array}$ & $\begin{array}{l}\text { N of } \\
\text { Items }\end{array}$ \\
\hline $\begin{array}{l}\text { Frequenc } \\
\mathbf{y}\end{array}$ & $\mathbf{. 8 9 0}$ & .883 & 43 \\
Severity & $\mathbf{. 8 0 1}$ & .799 & 43 \\
\hline
\end{tabular}

Figure 7 illustrate the most frequently occurring root causes of accidents in Tehran (top ten root causes). The results show 'cash flow and budget problems' and 'lack of relevant experience' are the most frequent root causes in Tehran construction projects. Moreover, results indicate that most frequent root causes occurred in 'subcontractor constraints' and 'project management responses, thus it should be considered. Figure 8 illustrate the most severe root causes of accidents in Tehran. The results show 'fail to supply safety equipment', 'inadequate budget for supervision construction process' and 'recruit untrained operative' are the most severe root causes in Tehran construction projects.

\subsection{Analytical Results on Implementation of Safety Program}

This finding indicates the implementation of safety program on Tehran construction site and finding the root causes of accident. The analysis will be classified into analysis on Worker Participation, safety prevention and control system, safety arrangement, safety commitment, Hazard analysis.

\subsubsection{Analysis on Worker Participation}

Workers play significant role in construction project. Moreover in safety program implementation, workers participation is so important. Motivated workers and workers with safety attitudes can be an effective part on safety program. Table 7 shows the implementation of Worker
Participation as a part on safety program. The result shows that 'workers rest area', 'workers safety attitudes' and 'workers motivation' just slightly extent implemented. However, the rest no extent implemented. Thus, based on respondents view workers participation on safety program in Tehran construction projects is poor and it needs to reorganise. The results of this research show same findings when comparing to Serdar Korkmaz et al. 2018.

\subsubsection{Analysis on Safety Prevention and Control System}

Safety prevention and control system is the core of an effective safety and health program. In fact, the analysis on safety prevention and control system will help on classifying what remedial action is essential to control them. The following analyses are used to identify and control workplace safety system: Efficient Enforcement Suitable Supervision, Safety Training, Equipment and Maintenance and Personal Competency. Table 8 shows the results on implementation of safety prevention and control system in Tehran construction sites. Table 8 shows the questionnaires survey analysis on safety prevention and control system. The problems as a result of safety prevention and control system in Tehran construction site shows by low rating between 2 and 1 . Insufficient medical service for workers, improper use of PPE, poor safety equipment maintenance and insufficient safety training for workers are the leading causes of accident in Tehran construction sites. This could be ascribed to shortage of cost provisions for safety.

\subsubsection{Analysis on Safety Arrangement}

Safety arrangement is one of the effective parts in safety program. The following analyses are used to identify and control workplace safety arrangement: Communication, Allocation of Authority and Responsibility, Adequate Resource Allocation. Table 9 shows the results on 


\section{Top 10 Most Frequent Root Causes}

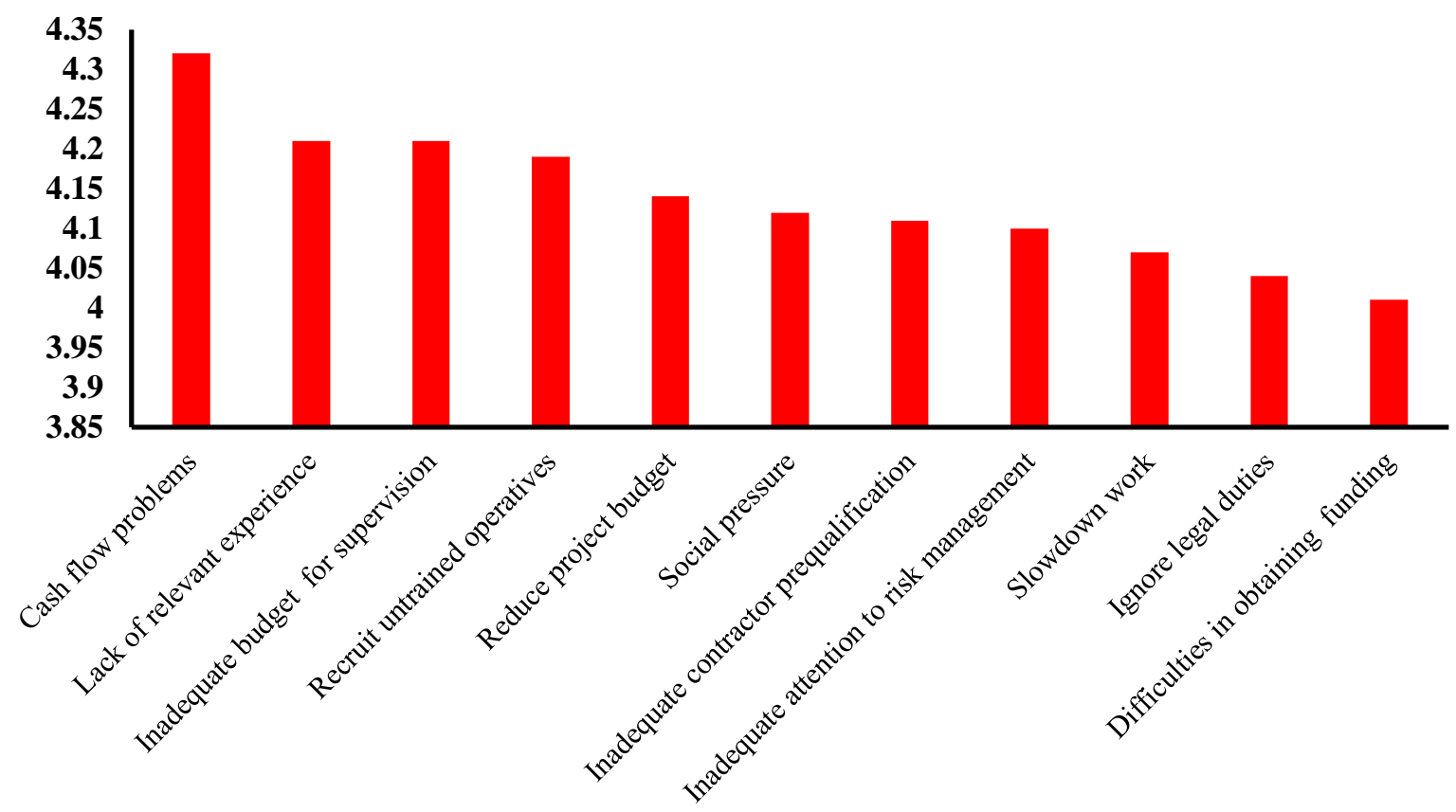

Figure 7: Top Ten Most Frequent Root Causes Occur in Tehran Construction Site

\section{Top 10 Most Sever Root Causes}

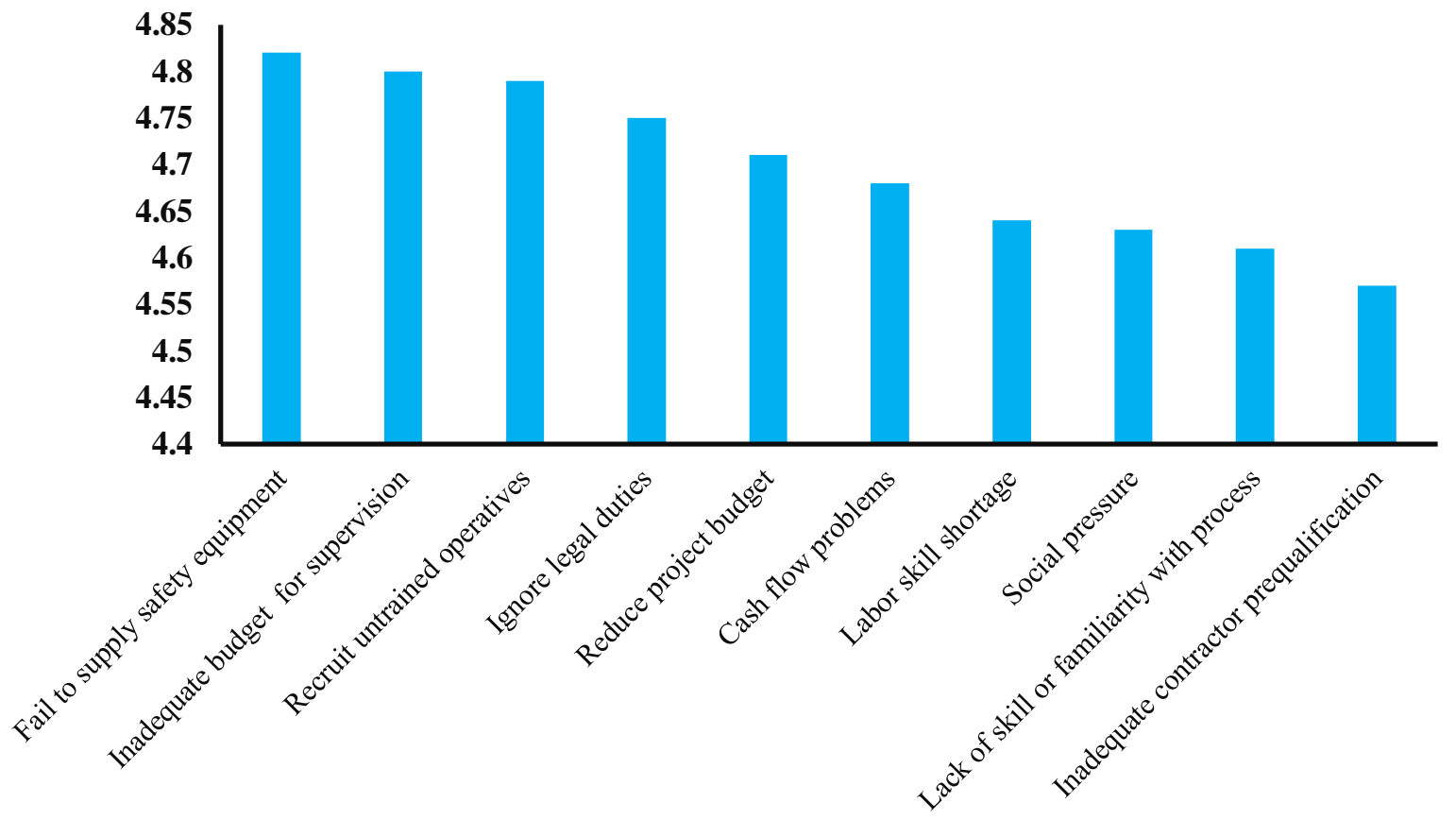

Figure 8: Top Ten Most Sever Root Causes Occur in Tehran Construction Site 
Table 7: Implementation of Worker Participation

\begin{tabular}{lcc}
\hline \multicolumn{1}{c}{ worker participation } & Rating & $\begin{array}{c}\text { Degree of } \\
\text { Implementation }\end{array}$ \\
\hline Is rest area (e.g. shelter and bed) provided for workers to rest? & 1.96 & Slightly \\
Do workers have safety attitudes? & 1.64 & Slightly \\
Are workers in the workplace motivated toward performing their jobs safely? & 1.54 & Slightly \\
\hline Is formal safety meeting held regularly to review the safety records? & 1.46 & Never \\
\hline Is Adopted punishment when a worker is found to have violated safety measures on site? & 1.46 & Never \\
Are workers allowed to make suggestions about the safety management scheme adopted on site? & 1.43 & Never \\
Do workers participate in identifying safety problems? & 1.21 & Never \\
Is given out monetary rewards for fewer accidents? & 1.21 & Never \\
Do workers participate in making decision towards the safety practices or programs which are to be & 1.07 & Never \\
adopted on site? & 1.07 & Never \\
Is reporting a hazard or an unsafe act on site rewarded? & 1.07 & Never \\
\hline Is counselling service provided for a worker who is stressed at work? & \\
\hline
\end{tabular}

Table 8: Implementation of prevention and control system

\begin{tabular}{|c|c|c|}
\hline safety prevention and control system & Rating & $\begin{array}{c}\text { Degree of } \\
\text { Implementation }\end{array}$ \\
\hline Are there any first-aid and medical services? & 1.79 & Slightly \\
\hline Is emphasized PPE usage to workers? & 1.75 & Slightly \\
\hline Are explained types of hazardous actions to workers? & 1.68 & Slightly \\
\hline Do all equipment and plant being used properly? & 1.61 & Slightly \\
\hline Are there supervisors who capable of allocating work that matches worker`s skill? & 1.57 & Slightly \\
\hline Is there safety training program for new personnel before staring their job? & 1.54 & Slightly \\
\hline $\begin{array}{l}\text { Is there regular maintenance of equipment to ensure that they are always in safe working } \\
\text { condition? }\end{array}$ & 1.50 & Slightly \\
\hline Are there any emergency response plans? & 1.50 & Slightly \\
\hline $\begin{array}{l}\text { Do management have personal competency to carry out the right thing at the right time by using } \\
\text { his/her sense, experience and skills to evaluate the hazard conditions and make a proper decision? }\end{array}$ & 1.46 & Never \\
\hline Is safety program monitored and reviewed to make sure that the safety goals are met? & 1.43 & Never \\
\hline $\begin{array}{l}\text { Are there any training programs which put in place to develop employees knowledge and skills } \\
\text { on safety at work? }\end{array}$ & 1.32 & Never \\
\hline Are older workers Sent for retraining? & 1.29 & Never \\
\hline
\end{tabular}

Table 9: Implementation of safety arrangement

\begin{tabular}{|c|c|c|}
\hline Safety Arrangement & Rating & $\begin{array}{c}\text { Degree of } \\
\text { Implementation }\end{array}$ \\
\hline $\begin{array}{l}\text { Is appropriate authority and responsibility assigned to workers in order to deal with safety } \\
\text { incidents and carry out appropriate actions? }\end{array}$ & 1.61 & Slightly \\
\hline $\begin{array}{l}\text { Are there any sufficient resources (e.g. staff, time, money, information, facilities, tools, machines) } \\
\text { to carry out day-to-day activities to accomplish both short-term and long-term goals? }\end{array}$ & 1.60 & Slightly \\
\hline $\begin{array}{l}\text { Are there any open communication between management and the middle-level and bottom-level } \\
\text { staff to facilitate prompt report? }\end{array}$ & 1.46 & Never \\
\hline \multicolumn{3}{|l|}{ Table 10: Implementation of Safety commitment } \\
\hline Safety Commitment & Rating & $\begin{array}{c}\text { Degree of } \\
\text { Implementation }\end{array}$ \\
\hline $\begin{array}{l}\text { Does management supply that sufficient resource is allocated for safety activities and that } \\
\text { regular safety meetings and training are in place? }\end{array}$ & 1.54 & Slightly \\
\hline Are all levels of staff in the company engaged in the safety programs? & 1.46 & Never \\
\hline $\begin{array}{l}\text { Are clear and reasonable safety goals established to provide a clear direction for staff to work } \\
\text { toward? }\end{array}$ & 1.43 & Never \\
\hline
\end{tabular}

Table 4.5 shows the questionnaires survey analysis on safety arrangement. The problems as a result of safety arrangement in Tehran construction site shows by low rating between 2 and 1. 'Inappropriate authority and responsibility is assigned to workers', 'insufficient resources to carry out dayto-day activities to accomplish both short-term and long-term goals' and 'lack of communication between management and the middle-level and bottom-level staff' are the leading causes of accident in Tehran construction sites.

\subsubsection{Analysis on Safety Commitment}

Safety commitment is one of the essential parts in safety program. The following analyses are used to identify and control workplace safety arrangement: Management Support, Teamwork and Clear and Reasonable Objective. Table 10 
shows the results on implementation of safety commitment in

Tehran construction sites.

Table 11: Implementation of Hazard analysis

\begin{tabular}{lcc}
\hline \multicolumn{1}{c}{ Record keeping } & Rating & Degree of Implementation \\
\hline Are all injuries and fatalities recorded? & 1.86 & Slightly \\
Are accidents investigated? & 1.71 & Slightly \\
Is safety inspection done regularly? & 1.64 & Slightly \\
Are medical records kept? & 1.57 & Slightly \\
Is hazard condition analysed? & 1.50 & Slightly \\
\hline
\end{tabular}

Table 10 shows the questionnaires survey analysis on safety arrangement. The problems as a result of safety commitment in Tehran construction site shows by low rating between 2 and 1. 'Insufficient resource is allocated for safety activities', 'lack of clear and reasonable safety goals' are the leading causes of accident in Tehran construction sites.

\subsubsection{Analysis on Record keeping}

Record keeping is one of the most vital parts of safety program that need more attention. Records should be up-todate and complete. Table 11 shows the implementation of safety requirement on record keeping in Tehran construction site.

As can be seen from table 11, most construction projects in Tehran have insufficient record on injuries and fatalities by rating between 1 and 2 . The problems shows from the analysis are insufficient injuries and fatalities record, insufficient medical record, inadequate accidents investigation. Injuries record will help the management to recognizing the appropriate accident requirement and investigation on workers. Therefore, suitable record keeping can provide to an effective safety and health program and preventing accidents in construction.

\section{Conclusion}

The severity and frequency of root causes in Tehran construction site were evaluated by using Likert Scale method. Based on results the most frequently and severe occurring root causes of accident were determined for identifying root causes of accident in Tehran construction projects. Based on results, root causes of accidents in Tehran construction sites are: 1) cash flow problems (subcontractor constraint); 2) inadequate budget for supervision (project management response); 3) lack of relevant experience (subcontractor constraint); 4) recruit untrained operatives (subcontractor response); 5) reduce project budget (client response); 6) social pressure (operative constraint); 7) fail to supply safety equipment (construction management response); 8 ) inadequate contractor prequalification (project management response); 9) lack of appropriate project experience (project management constraint); and 10) labour skill shortage (construction management constraint).

The severity of impact of root causes (proximal factors) in Tehran construction site was evaluated by using Likert Scale method. Based on results the most severe occurring proximal of accident was determined for identifying the impact of root causes of accident in Tehran construction projects. Based on results, the impact of root causes (proximal factors) of accidents in Tehran construction sites are: 1) improper or inadequate use of PPE; 2) annoyance, horseplay (operative action); 3) inadequate provision of PPE; 4) carelessness (operative action); 5) inadequate safety facilities; 6) inadequate provision of safety warning; 7) exceeding prescribed limits: load, strength, speed, etc.; 8) inadequate
Preparatory Training; 9) inadequate Control of Work site Condition; and 10) inadequate Control of the Stability of Temporary Structures.

The goal of safety program is to avoid the occurrence of accidents by setting down the appropriate safety standards. The safety program should be completely and to be maintained up-to-date. Based on the findings, the management in Tehran construction generally is not completely committed to safety and tried to neglect safety. Moreover, the department of labor's inspectors does not carry out regularly inspections. Also, the noticeable lack of commitment to safety and health by management has the potential for happening accidents which cause the safety program ineffective. The role of management in establishing an effective safety program is so significant. In fact, an effective safety program can assistance reducing site accidents which cause decrease financial loss, rise productivity and the most important thing is save lives of the workers.

\section{References}

Panagiotis Mitropoulos at el (2005). Systems Model of Construction Accident Causation: Journal of construction engineering and management $($ ) ASCE. Vol. 131, No. 7, 816-825.

Tariq S. Abdelhamid at el (2000). Identifying Root Causes of Construction Accidents. Journal of Construction Engineering and Management, Vol. 126, No. 1, 52-60.

T. Michael Toole at el (2000). Construction Site Safety Roles: Journal of Construction Engineering and Management, Vol. 128, No. 3, 203-210.

Fakhradin Ghasemi, Iraj Mohammadfam, Ali Reza Soltanian, Shahram Mahmoudi, Esmaeil Zarei, Surprising Incentive: An Instrument for Promoting Safety Performance of Construction Employees, Safety and Health at Work, Volume 6, Issue 3, 2015, Pages 227-232.

Xinyu Huang at el (2003). Analysis of Construction Worker Fall Accidents: Journal of Construction Engineering and Management, Vol. 129, No. 3, 262-271.

Patrick Manu at el (2010). An approach for determining the extent of contribution of construction project features to accident causation: Safety Science 48, 687-692.

Miguel A at el (2008). Construction industry accidents in Spain: Journal of Safety Research 39, 497-507

Abdul Rahim Abdul Hamid at el (2008). Causes of Accidents at Construction Sites: Malaysian Journal of Civil Engineering 20(2), $242-259$.

Akhmad Suraji at el (2001). Development of Causal Model of Construction Accident Causation: Journal of Construction Engineering and Management, Vol. 127, No. 4, 337-344.

Heinrich, H. W. (1969). Industrial accident prevention, 4th Ed, McGraw-Hill, New York.

Seok J. Yoon, Hsing K. Lin, Gang Chen, Shinjea Yi, Jeawook Choi, Zhenhua Rui, Effect of Occupational Health and Safety Management System on Work-Related Accident Rate and Differences of Occupational Health and Safety Management System Awareness between Managers in South Korea's Construction Industry, Safety and Health at Work, Volume 4, Issue 4, 2013, Pages 201-209.

Bird, F. (1974). "Management guide to loss control." International Safety Academy, Houston. 
Thanet Aksorn at el (2008). Critical success factors influencing safety program performance in Thai construction projects: Safety Science 46, 709-727.

S. AL HAADIR at el (2011). Critical Success Factors for Safety Program Implementation among Construction Companies in Saudi Arabia: Procedia Engineering 14, 148-155.

Diana N.C. Lai at el (2011). A comparative study on adopting human resource practices for safety management on construction projects in the United States and Singapore: International Journal of Project Management 29, 1018-1032

Abdul Rahim Abdul Hamid at el (2003). Hazards at Construction Sites: Proceedings of the 5th Asia-Pacific Structural Engineering and Construction Conference, Johor Bahru, Malaysia.

Sunku Venkata Siva Rajaprasad, Pasupulati Venkata Chalapathi, Factors Influencing Implementation of OHSAS 18001 in Indian Construction Organizations: Interpretive Structural Modeling Approach, Safety and Health at Work, Volume 6, Issue 3, 2015, Pages 200-205.

Zaherawati Zakaria at el (2010). Accidents at the Construction Site in Northern Area: Management Science and Engineering. Vol. 4, No. 3, 106-116.

Health and Safety Executive (HSE). (2002). Revitalizing Health and Safety in Construction (HSF Books:Sudbury, Suffolk).

A.Q. Adeleke, A.Y. Bahaudin, A.M. Kamaruddeen, J.A. Bamgbade, Maruf Gbadebo Salimon, Muhammad Waris Ali Khan, Shahryar Sorooshian, The Influence of Organizational External Factors on Construction Risk Management among Nigerian Construction Companies, Safety and Health at Work, Volume 9, Issue 1, 2018, Pages 115-124.

Charles Y.J. Cheah (2007). Construction Safety and Health Factors at the Industry Level: The Case of Singapore: Journal of Construction in Developing Countries, Vol. 12, No. 2.

Mr. Shinichi Hasegawa (2005), Regional Director of ILO Regional Office for Asia and the Pacific. http://www.ilo.org/global/lang-en/index.htm. International Labor Organisation professional website.

Mohammad Esabati. Director General Labor Inspection Department of Labor and Social Affairs http://www.shasa.ir. Iranian Construction News. Fara News Agency. 2010.

Shahram Mahmoudi, Fakhradin Ghasemi, Iraj Mohammadfam, Esmaeil Soleimani, Framework for Continuous Assessment and Improvement of Occupational Health and Safety Issues in Construction Companies, Safety and Health at Work, Volume 5, Issue 3, 2014, Pages 125-130.

Erik Hollnagel (2004). Barriers and accident prevention. Ashgate Publishing, Ltd., $2004-226$.

S.X. Zeng at el (2008). Towards occupational health and safety systems in the construction industry of China: Safety Science 46, 1155-1168.

Serdar Korkmaz, Dal Jae Park, Comparison of Safety Perception between Foreign and Local Workers in the Construction Industry in Republic of Korea, Safety and Health at Work, Volume 9, Issue 1, 2018, Pages 53-58.

Kwesi Amponsah-Tawiah, Michael Akomeah Ofori Ntow, Justice Mensah, Occupational Health and Safety Management and Turnover Intention in the Ghanaian Mining Sector, Safety and Health at Work, Volume 7, Issue 1, 2016, Pages 12-17. 